Aim Multiple studies affirm that Bystander CPR (BCPR) improves outcomes in Out-of-hospital Cardiac Arrest (OHCA). This study investigates age and other factors in affecting BCPR rates in Singapore.

Method Data was extracted from the national cardiac arrest registry. OHCA cases in Singapore conveyed via emergency medical services from April 2010-December 2015 were included. Zipcodes of arrest location, census data from 20102015 and planning areas were used for geospatial analysis. Multivariate logistic regression was performed to investigate the association between patient demographics and pre-hospital data with BCPR.

Results 8955 cases were split into 3 groups: Paediatric (Age 0-10 years; $n=107$ ), Young (Age $11-65$ years; $n=3979$ ), Old (Age $>65$ years; $n=4869$ ). Compared to the Old, Paediatric and Young patients had higher rates of BCPR (OR 3.997, 95\% CI: 2.567 to 6.224 ; OR 1.133, 95\% CI: 1.027 to 1.249). Non-traumatic arrest (OR 2.550, 95\% CI: 1.743 to 3.731) and Witnessed arrest (OR 1.267, 95\% CI: 1.157 to 1.387), positively associated with BCPR, while arrest in residential location (OR 0.655 , 95\% CI: 0.441 to 0.973 ) negatively associated with BCPR. Of the OHCA in residential locations, patients in neighbourhoods with younger population were more likely to receive BCPR (OR 1.242, 95\% CI: 1.061 to 1.453$)$ compared to older neighbourhoods. There was no association with gender and major race groups, and univariate analysis showed no difference in BCPR rates between family bystanders and other layperson bystanders.

Conclusion Older patients, residential arrests and older neighbourhoods were associated with lower rates of BCPR. Public education and training programs can be targeted to these populations to improve BCPR rates.

Conflict of interest None

Funding This study was supported by grants from National Medical Research Council, Clinician Scientist Award, Singapore (NMRC/CSA/024/2010 and NMRC/CSA/0049/2013), Ministry of Health, Health Services Research Grant, Singapore (HSRG/0021/2012) and Duke-NUS Khoo Research Student Award (Duke-NUS-KRSA/2013/0001).

\section{THE LONG TERM EFFECTS OF A 3-DAY FIRST AID PROGRAMME FOR 7-14 YEARS OLD PRIMARY SCHOOL CHILDREN}

'B Banfai*, 'A Pandur, 'B Schiszler, 'B Radnai, ${ }^{2} \mathrm{H}$ Banfai-Csonka, '1 Betlehem. ' University of Pécs Faculty of Health Sciences Institute of Emergency Care and Health Pedagogy, Hungary; ${ }^{2}$ University of Pécs, Department of Emergency Medicine, Hungary

\subsection{6/10.1136/bmjopen-2018-EMS.40}

Aim Bystanders can play an important role in the event of sudden injury or illness. Our aim was to evaluate the long term effects of a 3 day first aid programme for all primary school age groups (7-14 years old).

Method This study was a 15 months follow-up of our previous investigation. ${ }^{1}$ Five-hundred twenty-four primary school children were involved in this study (288 girls and 236 boys). Measurements were made in the following topics: adult basic life support, using an automated external defibrillator, handling an unconscious patient, managing bleeding and calling the ambulance. Data collection was made with a self-made questionnaire and observation.

Results Knowledge and skills after 15 months were significantly higher in the majority of the measured topics than before the programme $(p<0.01)$. However, results were significantly worse than immediately and 4 months after programme $(p<0.01)$. Younger children overall remembered less well than older children $(\mathrm{p}<0.01)$. Approximately three-third of children could use an AED, know the emergency phone number and the half of them could perform correct recovery position at 15 months. Correct assessment of breathing was similar than in baseline.

Conclusion This study was the most comprehensive longitudinal study so far conducted on the effects of first aid (not only resuscitation) programme among primary school children. Participants could remember some aspects of first aid long term. However, forgetting after 15 months was significant so refreshing trainings would be mandatory annually

\section{REFERENCE}

1. Banfai B, Pek E, Pandur A, Csonka H, Betlehem J. 'The year of first aid': Effectiveness of a 3-day first aid programme for 7-14-year-old primary school children. Emerg Med J 2017;34:526-32.

Conflict of interest None

Funding None

\section{IS IT NECESSARY? - OPINIONS AND EXPERIENCES ABOUT FIRST AID EDUCATION IN CHILDHOOD - PILOT STUDY}

${ }^{1}$ B Banfai*, ' A Pandur, 'B Schiszler, 'B Radnai, ${ }^{2} \mathrm{H}$ Banfai-Csonka, ${ }^{1} \mathrm{~J}$ Betlehem. 'University of Pécs Faculty of Health Sciences Institute of Emergency Care and Health Pedagogy, Hungary; ${ }^{2}$ University of Pécs, Department of Emergency Medicine, Hungary

\subsection{6/10.1136/bmjopen-2018-EMS.41}

Aim Starting first aid education in early childhood can be an effective method of knowledge transfer. Our aim was to examine first aid education related opinions of kindergartenand primary school children, educators, and parents.

Method Eight-hundred seventy-one people (700 kindergartenand primary school children, 29 educators, 142 parents) were involved in our study. Opinions were measured with selfedited questionnaires, containing mainly open questions.

Results Based on the answers, the majority of children (90\%) enjoyed our programme, they would like to participate further first aid programmes in the future. General opinions of parents and educators about first aid education in childhood were mainly positive, but they also gave negative ones. The majority of participants $(>90 \%)$ had a positive opinion about our completed programme. ${ }^{1}$ Based on the opinions of parents and educators first aid education is recommended by health care professionals. Opinions were independent from gender $(p=0.302)$, age $(p=0.512)$, time of working with children $(\mathrm{p}=0.251)$.

Conclusion Children's opinion about the first aid programme were mainly positive. General opinions of parents and educators were different, but were positive related our programme. Based on this results opinions can change with concrete activities and can make first aid education more popular/acceptable by laypeople. 


\section{REFERENCE}

1. Banfai B, Pek E, Pandur A, Csonka H, Betlehem J. 'The year of first aid': Effectiveness of a 3-day first aid programme for 7-14-year-old primary school children. Emerg Med J 2017;34:526-32.

Conflict of interest None

Funding None

\section{EFFECTS OF A GENERAL PRACTITIONER AT SCENES OF SERIOUS INJURY: A SYSTEMATIC REVIEW}

${ }^{1}$ Gyri Synnøve Hval Straumann*, ${ }^{1}$ Astrid Austvoll-Dahlgren, ${ }^{1}$ Hilde Helene Holte 2,3,4 Torben Wisborg. ${ }^{1}$ Norwegian Institute of Public Health, Oslo, Norway; ${ }^{2}$ Norwegian National Advisory Unit on Trauma, Division of Emergencies and Critical Care, Oslo University Hospital, Oslo, Norway; ${ }^{3}$ Anaesthesia and Critical Care Research Group, Faculty of Health Sciences, University of Tromso, Norway; ${ }^{4}$ Hammerfest Hospital, Department of Anaesthesiology and Intensive Care, Finnmark Health Trust, Hammerfest, Norway

\subsection{6/10.1136/bmjopen-2018-EMS.42}

Aim In Norway, each municipality is responsible for first line emergency healthcare, and has to have a general practitioner (GP) on call continuously. GPs are expected to assist patients and ambulance personnel at the site of severe injuries or illnesses. The Norwegian society invests substantial resources into emergency care, and it is desirable to find evidence to inform this practice. This systematic review aimed to examine how survival, time spent at the scene, the choice of transport destination, assessment of urgency, the number of admissions, and the number of cancellations of specialised prehospital resources were affected by the presence of a GP at the scene of a suspected severe injury.

Method This systematic review utilised systematic, transparent methods. ${ }^{1}$ We searched published and planned systematic reviews and primary studies in Cochrane Library, Medline, Embase, OpenGrey, GreyLit and trial registries in June 2016. Two authors independently screened the references and assessed the eligibility of all potentially relevant studies. The inclusion criteria for study design was based on the Cochrane Effective Practice and Organisation of Care Group (EPOC). ${ }^{2}$

Results The search for systematic reviews and primary studies identified 5415 articles. However, no studies met the predefined inclusion criteria. Most studies were excluded because they did not investigate either the target population (severely injured) or the intervention in question (presence of a general practitioner).

Conclusion It remains uncertain how the presence of a general practitioner at the injury scene might affect the selected outcomes.

\section{REFERENCES}

1. Norwegian Knowledge Centre for the Health Services. This is how we summarise research (Slik oppsummerer vi forskning). Handbook for Norwegian Knowledge Centre for the Health Services 4th ed. 2015, Oslo.

2. What study designs should be included in an EPOC review and what should they be called? EPOC Resources for review authors. Oslo: Norwegian Knowledge Centre for the Health Services, 2017. (Accessed 15. February 2017, at http:// epoc.cochrane.org/epoc-specific-resources-review-authors.)

\section{GLOBAL RESUSCITATION ALLIANCE UTSTEIN RECOMMENDATIONS FOR DEVELOPING EMERGENCY MEDICAL SERVICES SYSTEMS TO IMPROVE CARDIAC ARREST SURVIVAL}

${ }^{1} \mathrm{~N}$ Gayathri ${ }^{*},{ }^{2} \mathrm{~L}$ Tiah, ${ }^{3} \mathrm{AFW}$ Ho, ${ }^{4} \mathrm{~A}$ Ajaz, ${ }^{5} \mathrm{HM}$ Ohn, ${ }^{6} \mathrm{KD}$ Wong, ${ }^{7} \mathrm{LA}$ Wallis, ${ }^{8} \mathrm{BS}$ Leong, ${ }^{9} \mathrm{~F}$ Lippert, ${ }^{10} \mathrm{M}$ Castren, ${ }^{11} \mathrm{MHM} \mathrm{Ma},{ }^{12} \mathrm{MJ}$ El Sayed, ${ }^{1} \mathrm{PP}$ Pek, ${ }^{13} \mathrm{~J}$ Overton, ${ }^{14} \mathrm{~S}$ Perret, ${ }^{15} \mathrm{~T}$ Hara, ${ }^{16} \mathrm{YY} \mathrm{Ng},{ }^{17} \mathrm{MEH}$ Ong. 'Singapore General Hospital, Department of Emergency Medicine, Singapore; ${ }^{2}$ Changi General Hospital, Accident and Emergency Department, Singapore; ${ }^{3}$ Singhealth Emergency Medicine Residency, Singapore; ${ }^{4}$ Addis Ababa University School of Medicine, Department of Emergency Medicine, Ethiopia; ${ }^{5}$ Parami General Hospital, Emergency Department, Yangon, Myanmar, ${ }^{6}$ Hospital Pulau Pinang, Emergency and Trauma Department, George Town, Penang, Malaysia; 'University of Cape Town, Division of Emergency Medicine, CapeTown, South Africa; ${ }^{8}$ National University Hospital, Emergency Medicine Department, Singapore; ${ }^{9}$ University of Copenhagen, Emergency Medical Services Copenhagen, Copenhagen, Denmark; ${ }^{10}$ Karolinska Institutet, Department of Clinical Science and Education, Stockholm, Sweden; University of Helsinki and Helsinki University Hospital, Department of Emergency Medicine and Services, Helsinki, Finland; ${ }^{11}$ College of Medicine, National Taiwan University, Department of Emergency Medicine, Taipei, Taiwan; ${ }^{12}$ American University of Beirut Medical Centre, Department of Emergency Medicine, Beirut, Lebanon; ${ }^{13}$ International Academies of Emergency Dispatch, Salt Lake City, Utah, USA; ${ }^{14}$ Vientiane Rescue, Vientiane, Laos; ${ }^{15}$ Graduate School, Kokushikan University, Department of EMS System, Tokyo, Japan; ${ }^{16}$ Singapore Civil Defence Force, Singapore; ${ }^{17}$ Singapore General Hospital, Department of Emergency Medicine, Singapore; Duke-NUS Medical School, Health Services and Systems Research, Duke-NUS Medical School, Singapore

\subsection{6/10.1136/bmjopen-2018-EMS.43}

Aim The Global Resuscitation Alliance (GRA) 10 steps were established in 2015 to improve survival for Out-of-Hospital Cardiac Arrest (OHCA). However, these 10 steps were recommended mainly for developed Emergency Medical Services (EMS) systems and implementing these steps can be challenging for developing EMS systems. We aimed to explore barriers faced by developing EMS systems and to establish pre-requisites needed to improve survival. We also developed a framework for developing EMS systems to build their emergency response capability.

Method A consensus meeting was called in Singapore on $1 \mathrm{st}$ and 2nd August 2017. There were 74 participants who were key stakeholders from 26 countries including EMS directors, physicians and academics. The group was subdivided into 4 groups to represent the chain of survival- community, dispatch, ambulance and hospital, with a separate group on perinatal resuscitation. Pertinent questions were given to the group for discussion, following which their answers were presented and voted upon to reach a consensus.

Results Each group's discussion points were used to construct the modified survival framework and create 11 key statements to describe the pre-requisites for achieving the GRA 10 steps. The participants then voted on the importance and feasibility of these 11 statements as well as the GRA 10 steps.

Conclusion In this paper, we propose a modified framework of survival for developing EMS systems. There are barriers for developing EMS systems to improve OHCA survival rates. These barriers may be overcome by systematic prioritisation and cost effective innovative solutions.

Conflict of interest None

Funding The consensus meeting was support by the Laerdal Foundation grant, grant no: 50005

Conflict of interest None

Funding None 